\title{
FT-IR Characterization of Pollen Biochemistry, Viability, and Germination Capacity in Saintpaulia H. Wendl. Genotypes
}

\author{
Erzsebet Buta, ${ }^{1}$ Maria Cantor, ${ }^{1}$ Răzvan Ștefan, ${ }^{2}$ Rodica Pop, ${ }^{1}$ Ioana Mitre Jr., \\ Mihai Buta, ${ }^{3}$ and Radu E. Sestraş ${ }^{1}$ \\ ${ }^{1}$ Faculty of Horticulture, University of Agricultural Sciences and Veterinary Medicine Cluj-Napoca, 3-5 Mănăştur, \\ 400372 Cluj-Napoca, Romania \\ ${ }^{2}$ Faculty of Veterinary Medicine, University of Agricultural Sciences and Veterinary Medicine Cluj-Napoca, 3-5 Mănăştur, \\ 400372 Cluj-Napoca, Romania \\ ${ }^{3}$ Faculty of Agriculture, University of Agricultural Sciences and Veterinary Medicine Cluj-Napoca, 3-5 Mănăștur, \\ 400372 Cluj-Napoca, Romania
}

Correspondence should be addressed to Radu E. Sestraş; rsestras@usamvcluj.ro

Received 1 June 2015; Accepted 21 July 2015

Academic Editor: Daniel Cozzolino

Copyright (C) 2015 Erzsebet Buta et al. This is an open access article distributed under the Creative Commons Attribution License, which permits unrestricted use, distribution, and reproduction in any medium, provided the original work is properly cited.

FT-IR characterization of pollen biochemistry was analyzed to detect possible connection with the viability (by staining with potassium iodide, 25\%) and the germination capacity (on solid nutrient medium), in 15 Saintpaulia genotypes. Vibrational spectroscopy indicates that the pollen of $S$. ionantha genotype "Red Velvet" is rich in proteins, lipids, triglycerides, and esters and has a viability of $88.4 \%$ and a low germination capacity (27.16\%). For S. ionantha "Jolly Red" and "Lucky Ladybug" genotypes, pollen showed high viability (88.81-91.49\%) and low germination capacity (23.02-9.17\%), even though the pollen is rich in carbohydrates. S. ionantha "Aloha Orchid" genotype has the highest percentage of viability (94.32\%) and germination capacity (45.73\%) and a rich content of carbohydrates and polygalacturonic acids. In S. rupicola and S. ionantha genotypes, the rich content of polygalacturonic acids, lipids, and carbohydrates favourably influenced the germination capacity. Spectroscopic result indicates, through different absorbance band intensity, a possible link between biochemical composition, viability, and germination capacity of Saintpaulia pollen. To determine exactly the relation between biochemistry and biological processes, it is necessary to initiate quantitative researches.

\section{Introduction}

The Saintpaulia (H. Wendl.) genus has an important economical and ornamental value, both in Romania and in various European countries $[1,2]$. This is reflected by the presence of 2000 existing cultivars [3] and the interest of breeders to create and obtain new cultivars with superior morphological characters. African violets are the most popular indoor plants $[1,4]$, preferred for their tolerance to north exposures, their relatively quick and easy propagation, their flowering throughout the year, and their permanent decor through their flowers and leaves [5].

African violet (Saintpaulia H. Wendl.) is native to Eastern Africa [6, 7], tropical Africa [8], Tanzania, and Kenya [3]. It is an angiosperm of the order Lamiales, in the family Gesneriaceae $[2,9]$. Much data exists on vegetative propagation of Saintpaulia genotypes $[1,2,7,10,11]$ but only a few studies refer to their palynological analysis.

In order to identify chemical compounds of different biological materials such pollen $[12,13]$, FT-IR spectroscopy is one of the most widely used methods. According to dedicate literature $[14,15]$, this analytical process was used to identify $[16,17]$, determine, classify, discriminate, and characterize $[18,19]$ pollen of many ornamental plants. The relative biochemical composition using FT-IR [20], germinability, and pollen viability has been studied in various ornamental plants [21-25], including different species from the conifers, 
TABLE 1: The morphology of Saintpaulia genotypes.

\begin{tabular}{|c|c|c|c|}
\hline Code & Genotype & Flower colour* & Brief description $[4,6]$ \\
\hline S1 & S. ionantha "Red Velvet" & Deep pink 52B & Single flower, medium green foliage \\
\hline S2 & S. ionantha "Jolly Red" & Strong red 53B & Single flower, light green foliage \\
\hline S3 & S. ionantha "Aloha Orchid" & Light purple RHS 77D & Semidouble flower, medium green foliage \\
\hline S4 & S. ionantha "Hot Pink Bell" & Light pink 39D & Single flower, dark green foliage \\
\hline S5 & S. ionantha "Park Avenue Blue" & $\begin{array}{l}\text { Signal violet RHS 77D and } \\
\text { greenish white 155C }\end{array}$ & $\begin{array}{l}\text { Single flower, dark blue with a white eye on the middle of corolla, } \\
\text { medium green foliage }\end{array}$ \\
\hline S6 & S. ionantha "Lucky Ladybug" & Strong red 53B & Single flower, dark green, quilted foliage \\
\hline S7 & S. ionantha "Crimson Ice" & Light pink 39D & $\begin{array}{l}\text { Single flower, white with pink thumbprint on each petal, and dark } \\
\text { green foliage }\end{array}$ \\
\hline S8 & S. ionantha H. Wendl. & Strong violet RHS 90B & Violet single flower, dark green foliage \\
\hline S9 & S. ionantha "White Queen" & Greenish white $155 \mathrm{C}$ & Double flower, light green foliage \\
\hline S10 & S. ionantha "Painted Silk" & Strong violet RHS 90B & Single flower, light green girl-type foliage \\
\hline S11 & S. ionantha "Pink Pussycat" & Light pink 39D & Single flower, dark green foliage \\
\hline S12 & S. ionantha "Buffalo Hunt" & Strong red 39D & Semidouble flowers, with a slightly ruffled edge; foliage is dark green \\
\hline S13 & S. rupicola B. L. Burtt & Strong violet RHS 90B & Double flower, long stalk, and light green foliage \\
\hline S14 & S. ionantha "Tomahawks" & Strong red 39D & Semidouble, bright red, dark green foliage \\
\hline S15 & S. grotei Engl. & Light blue RHS 104D & Single small flowers, light green foliage \\
\hline
\end{tabular}

${ }^{*}$ The colours of genotypes were established according to the RHS colour chart.

monocotyledons, eudicots, and magnoliids [16]; however these studies do not include the Saintpaulia genus.

This paper is a comprehensive study of pollen belonging to 15 African violet genotypes. The lack of consistent and relevant data on bioactive elements of Saintpaulia pollen and also their connection on the viability and germination make this a pioneer study, and the results obtained allow a selection of valuable genotypes for breeding programs.

\section{Material and Methods}

2.1. Plant Material. In order to investigate the chemical composition, viability, and germination capacity, pollen was collected in October from the mature anthers of 15 genotypes of Saintpaulia ionantha $\mathrm{H}$. Wendl. (Table 1). The plants were cultivated under the same environmental conditions (84\% average air humidity and $23^{\circ} \mathrm{C}$ average temperature) at the didactic greenhouse of the Department of Floriculture within the University of Agricultural Sciences and Veterinary Medicine Cluj-Napoca (UASMVCN).

2.2. Biochemical Composition. The research of spectral differentiation in pollen grain biochemistry was conducted in the Raman and IR Spectrometry Laboratory, at the UASMVCN, with the FT/IR-4100 spectrometer (Jasco Analytical Instruments, Easton, USA), with a spectral region between 4000 and $350 \mathrm{~cm}^{-1}$ and a resolution of $4 \mathrm{~cm}^{-1}$. The pellet mode was chosen, in which the pollen samples $(3 \mathrm{mg}$ ) were mixed with $200 \mathrm{mg}$ of potassium bromide and then compressed into tablets (Specac, IR accessory for producing pills) [13]. For each experimental sample (S1…S15), 264 scans were made and one final IR spectrum was illustrated in Figures 1-3.

The Spectra Manager software package was used for scanning samples. The data were processed using ORIGIN 8.5 Pro software.
2.3. Pollen Viability. In order to determine the viability test, the collected anthers were put in a Carnoy solution for 2 hours, after which they were washed in $80 \%$ ethyl alcohol. The determination of pollen viability was obtained by staining with potassium iodide (25\%). Pollen viability was obtained by staining with potassium iodide (25\%). The brown pollen was considered viable, and the colourless one unviable [26-28]. The pollen quantification was made by observing the pollen in ten fields in each of five replications using Aigo Digital Microscope EV5610.

2.4. Pollen Germination. The germination and pollen viability were evaluated in accordance with the methodologies described by Gudadhe and Dhoran [23], Bodhipadma et al. [29], and Cordea [28]. The germination of pollen was performed on solid nutrient medium (15\% sucrose, $85 \%$ humidity, and $22^{\circ} \mathrm{C}$ temperature), and their counting was done using an electronic microscope (Aigo Digital Microscope EV5610, Beijing Research Institute of Precision Instrument Aigo Co., Ltd.). Counts were made in ten fields in each of five replications. The total number of grains on the field and the number of the germinated and the ungerminated pollens were recorded $[27,28]$.

Data on viability and germination of Saintpaulia pollen were analysed using the ANOVA test, where significant differences between mean values were separated using the Duncan's test.

\section{Results and Discussions}

3.1. The Biochemical Composition of Saintpaulia Pollen. Fourier transform infrared spectroscopy (FT-IR) is modern analytical method, allowing rapid examination of the relative biochemical compositions of pollen or other biological material $[12,13]$. The biomolecular constituents of pollen, which can be 
TABLE 2: The spectral bands assignment using the FT-IR method, in the case of Saintpaulia genotypes.

\begin{tabular}{lcl}
\hline Spectral zone & Peak frequency cm & Chemical bonds \\
\hline$\approx 1,730 \mathrm{~cm}^{-1}$ & $\mathrm{C}=\mathrm{O}$ stretch (lipids, triglycerides, and alkyl-esters) \\
$1,660-1,666 \mathrm{~cm}^{-1}$ & $\mathrm{C}=\mathrm{O}$ stretch (amide I-proteins) \\
$1,800-1,500 \mathrm{~cm}^{-1}$ & $\mathrm{COO}^{-}$antisymmetric stretch (acidic group of polygalacturonic acids) \\
$1,540-1,550 \mathrm{~cm}^{-1}$ & $\mathrm{~N}-\mathrm{H}$ deformation; C-N stretch (amide II, proteins and lignin) \\
$\approx 1,514 \mathrm{~cm}^{-1}$ & $\mathrm{C}=\mathrm{C}-\mathrm{C}$ (approximation of aromatic ring bonding) (sporopollenin) \\
\hline $1,416-1,418 \mathrm{~cm}^{-1}$ & $\mathrm{COO}-$ symmetric stretch (acidic group of polygalacturonic acids) \\
$1,440-1,450 \mathrm{~cm}^{-1}$ & $\mathrm{CH}, \mathrm{CH}$ deformation (acidic group of polygalacturonic acids) \\
$1,318-1,321 \mathrm{~cm}^{-1}$ & $(\mathrm{C}-\mathrm{C}, \mathrm{C}-\mathrm{O})$ (acetylenic compounds) \\
$1,255-1,257 \mathrm{~cm}^{-1}$ & $\mathrm{C}-\mathrm{O}-\mathrm{H}$ deformation; C=O stretching of phenolics (lipids and triglycerides, pectins, \\
$1,400-1,000 \mathrm{~cm}^{-1}$ & and carbohydrate molecule) \\
$1,104-1,106 \mathrm{~cm}^{-1}$ & $\mathrm{C}-\mathrm{OH}$ skeletal; C-O-C sugar ring (carbohydrate molecule) \\
$1,050-1,055 \mathrm{~cm}^{-1}$ & $\mathrm{C}-\mathrm{O}-\mathrm{C}$ stretch; C-OH stretch; C-OH deformation; C-O-C deformation, \\
pyranose, and furanose ring (carbohydrate molecule)
\end{tabular}

${ }^{*}$ See assignment in text.

identified by this method, are lipids, proteins, carbohydrates, and sporopollenin. These are the main structural and nutritional elements of pollen responsible for the majority of the phenotypical, physiological, and biochemical manifestations $[16,30]$.

Previous studies have shown that there are significant differences at the level of the biochemical composition of pollen belonging to related species; however there are few studies on the biochemical differences of pollen between genotypes of the same genus [18]. For the 15 samples of Saintpaulia pollen, it was established that, in order to describe the molecular vibrations, the area of analysis of the spectral region is $1,800-$ $800 \mathrm{~cm}^{-1}$ (Table 2, Figures 1-3). The genotypes were arranged in three groups: I (S1, S2, S6, S12, and S14), II (S3, S8, S10, S13, and S15), and III (S4, S5, S7, S9, and S11) based on their colours.

For the first group of plants, the zone between 1,800 and $1,500 \mathrm{~cm}^{-1}$ is characterized by the presence of a band with a value around $1,730 \mathrm{~cm}^{-1}$ (S1, S12, and S14) and two bands for the $1,660-1,500 \mathrm{~cm}^{-1}$ zone (Figure 1). The band at $1730 \mathrm{~cm}^{-1}$ $(\mathrm{C}=\mathrm{O}$ stretch $)$ indicates the presence of lipids, triglycerides, and alkyl-esters, according to Yang and Yen [31] and Mularczyk-Oliwa et al. [12]. Proteins are characterized by a strong band at $1,666 \mathrm{~cm}^{-1}$ (amide I: C=O stretch) in sample S1 $[12,16]$. Notably, the pollen grains of this genotype have rich protein content, the most important nutritional indicator of pollen [30]. The presence of aromatic rings from sporopollenin is also observed, in the same spectral area, by the appearance of the absorption band of $1,514 \mathrm{~cm}^{-1}$, described by Zimmermann and Kohler [18] (Table 2, Figure 1).

In the spectral region of $1,500-900 \mathrm{~cm}^{-1}$ a prominent band around the value of $1,400 \mathrm{~cm}^{-1}\left(\mathrm{COO}^{-}\right.$stretch and $\mathrm{CH}_{2}$ and $\mathrm{CH}_{3}$ deformation) appeared, which is attributed to the

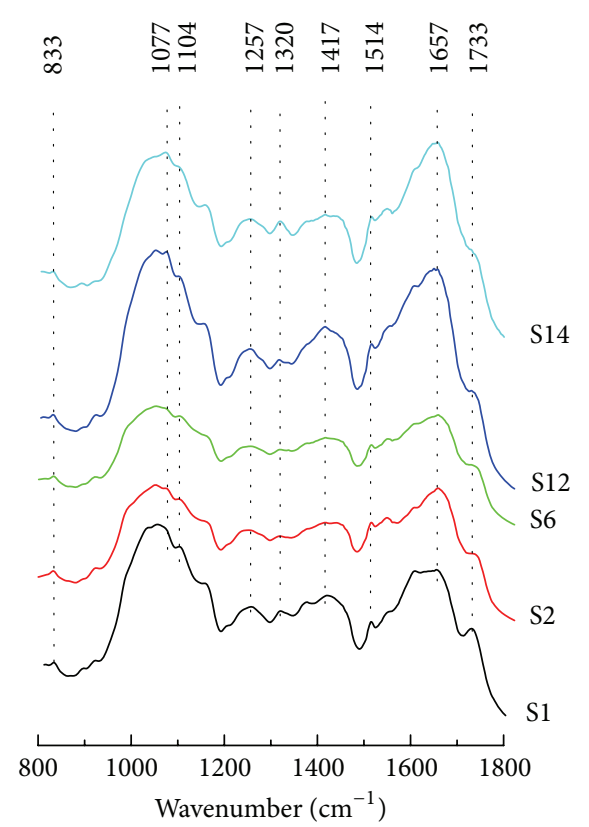

FIGURE 1: The FT-IR absorption bands of the spectral region 1,800$800 \mathrm{~cm}^{-1}\left(4 \mathrm{~cm}^{-1}\right.$ resolution) of Saintpaulia genotypes pollen for the plants of the first group.

presence of lipids and triglycerides, observed by MularczykOliwa et al. [12] and Zimmermann and Kohler [16]. The peak of $1,318 \mathrm{~cm}^{-1}$ is attributed to the presence of acetylenic compounds $[12,32]$. The signal at $1,255 \mathrm{~cm}^{-1}$ is associated with carbohydrates molecules [31, 33]. The most intense band in this spectral region is at $1,106 \mathrm{~cm}^{-1}(\mathrm{C}-\mathrm{OH}$ skeletal; $\mathrm{C}-\mathrm{O}-\mathrm{C})$ 


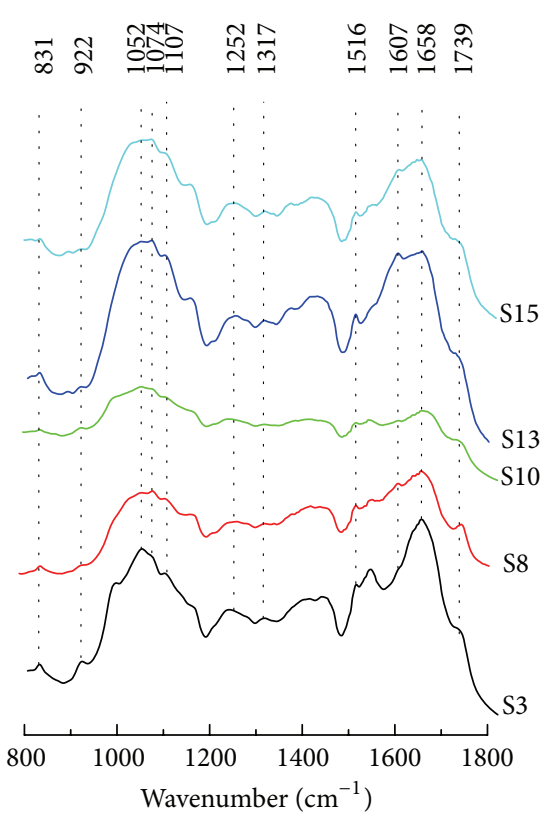

FIGURE 2: The FT-IR spectral bands assignment in the 1,800$800 \mathrm{~cm}^{-1}$ zone $\left(4 \mathrm{~cm}^{-1}\right.$ resolution) in the Saintpaulia genotypes of pollen from the second group of plants.

in S6 and S12 samples [12]. Carbohydrate molecules can also be observed, around the band of $830 \mathrm{~cm}^{-1}(\mathrm{C}-\mathrm{O}-\mathrm{C})$.

For the second group of plants (Figure 2), a strong vibration was observed around the value of $1,740 \mathrm{~cm}^{-1}$. This vibration is better defined in the $S 8$ genotype moving unvaryingly to $1,732 \mathrm{~cm}^{-1}$ (S15). The presence of amide I was noticed through $\mathrm{C}=\mathrm{O}$ stretch band around $1,660 \mathrm{~cm}^{-1}$, as illustrated by several authors $[12,18,34]$.

The spectral band at $1,608 \mathrm{~cm}^{-1}\left(\mathrm{COO}^{-}\right.$antisymmetric stretch) was more visible in S8 and S15 genotypes, while in S3 it appears as a shoulder and can be associated with the vibration of polygalacturonic acids. The absorption band of $1,517 \mathrm{~cm}^{-1}$ was found in all genotypes from this group of plants, being correlated to the presence of aromatic rings from sporopollenin [18].

Genotypes S13 and S15 presented strong vibrations around the value of $1,318 \mathrm{~cm}^{-1}$ (C-O skeletal), attributed to the existence of acetylenic compounds, as reported by Coates [32] and Mularczyk-Oliwa et al. [12]. The vibrations around $1,241 \mathrm{~cm}^{-1}$ and $1,255 \mathrm{~cm}^{-1}$ (C-O stretch) are generated by lipids and triglycerides [19]. In the spectral region of $1,100 \mathrm{~cm}^{-1}$, the most well-defined vibrational bands are located at $1,055 \mathrm{~cm}^{-1}$ (S3 genotype). These bands unvaryingly moved towards $1,074 \mathrm{~cm}^{-1}$ in S8 and $S 10$ and $1,077 \mathrm{~cm}^{-1}$ for $\mathrm{S} 13$ and S15, attributed to the carbohydrates content according to Zimmermann and Kohler [16]. Stronger vibrations were observed in S8, S13, and S15, which represent three important species in breeding (S. grotei, S. ionantha, and S. rupicola). Carbohydrates molecules are associated with values $922 \mathrm{~cm}^{-1}$ and $830 \mathrm{~cm}^{-1}(\mathrm{C}-\mathrm{O}-\mathrm{C})$.

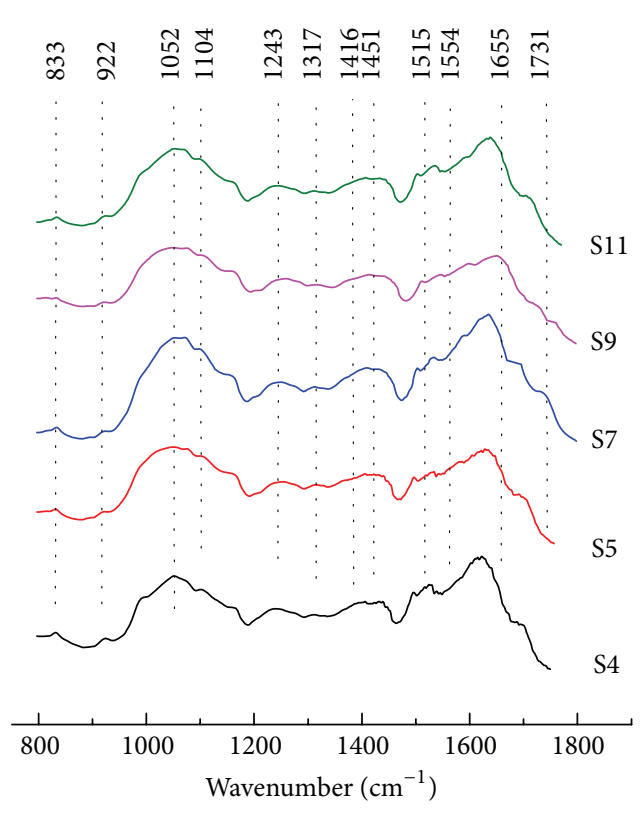

FIGURE 3: The molecular vibrations in pollen samples at $1,800-$ $800 \mathrm{~cm}^{-1}$ region $\left(4 \mathrm{~cm}^{-1}\right.$ resolution) in Saintpaulia genotypes from the third group of plants.

In the third group of plants, for S4 and S5, there were two strong bands in the $1,550 \mathrm{~cm}^{-1}$ region, which are characterized by the presence of proteins (amide II: $\mathrm{N}-\mathrm{H}$ deformation, C-N stretch) as indicated by Mularczyk-Oliwa et al. [12] and Zimmermann and Kohler [18] (Figure 3).

The presence of aromatic rings in sporopollenin is visibly delimited around the value of $1,515 \mathrm{~cm}^{-1}$ in all genotypes [16]. Two peaks appeared in S4 and S5 genotypes at $1,416 \mathrm{~cm}^{-1}$ $\left(\mathrm{COO}^{-}\right.$symmetric stretch) and $1,450 \mathrm{~cm}^{-1}\left(\mathrm{CH}_{2}, \mathrm{CH}_{3}\right.$ deformations), the result of the presence of polygalacturonic acids. The presence of the signal at $1,257 \mathrm{~cm}^{-1}$ is usually associated with lipids, triglycerides, and carbohydrates molecules. The absorption band between 1,318 and $1,321 \mathrm{~cm}^{-1}$ (C-C, C-O) is associated with the existence of acetylenic compounds $[12,32]$.

The carbohydrate band is presented around 1,055$836 \mathrm{~cm}^{-1}$ through $\mathrm{C}-\mathrm{O}-\mathrm{C}$ stretch, $\mathrm{C}-\mathrm{OH}$ stretch, $\mathrm{C}-\mathrm{OH}$ deformation, $\mathrm{C}-\mathrm{O}-\mathrm{C}$ deformation, pyranose and furanose ring, and $\alpha$-glycosidic and $\beta$-glycosidic vibrations, confirmed by Mularczyk-Oliwa et al. [12] and Zimmermann and Kohler [18].

The most important bioactive elements were present in all the 15 Saintpaulia genotypes analyzed, but the spectral intensity between their characteristic bands substantially varies as demonstrated by Zimmermann and Kohler [16] and confirmed by Žilić et al. [30].

3.2. Pollen Viability of Saintpaulia Genotypes. Pollen quality analyzed through the viability perspective and germination capacity can offer important information for breeders, 


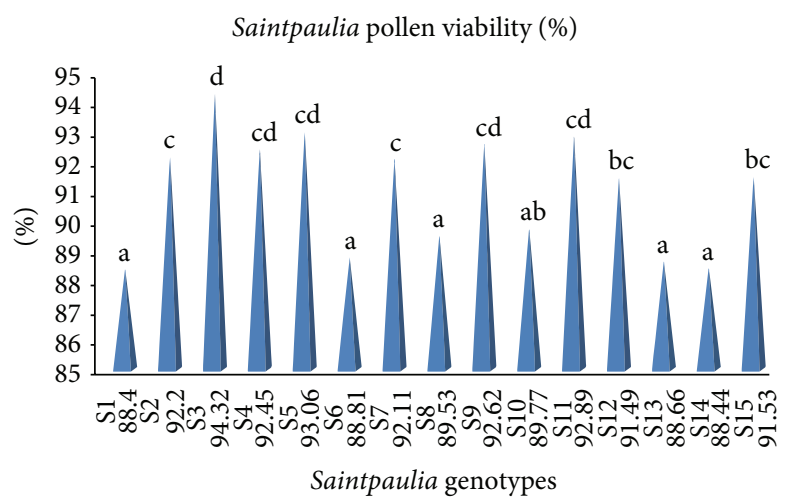

Figure 4: Percentage of pollen viability in 15 genotypes of Saintpaulia using the potassium iodide stain method (25\%). ${ }^{*}$ Values are means of 5 replications \pm SD (1.77-2.05). Small letters represent the statistical significant differences at $P<0.05$ (Duncan's test).

geneticists, and growers [34, 35]. According to RodriguezRiano and Dafni [36] and Firmage and Dafni [37], the pollen viability depends on the staining method and on species.

The highest percentage of viability was recorded in S3 (94.32\%), distinguishing itself by the rich content of carbohydrates (Figures 2 and 4 ). The same high viability was recorded in S4, S5, S9, and S11 genotypes, not differing statistically from S3. The lowest viability percentage was recorded in S1 $(88.40 \%)$, even if the pollen grain of this genotype has a high content of proteins. Genotypes S6, S8, S10, S13, and S14 had percentage of viability similar to that in S1 (Figure 4).

3.3. Pollen Germination of Saintpaulia Genotypes. For evaluation of the maximum germination potential and the proper development of the pollen tube, the most quick, simple, and complete method is in vitro demonstrated and confirmed by Fei and Nelson [38], De Assis Sinimbú Neto et al. [39], Ahmad et al. [40], Gudadhe and Dhoran [23], Bodhipadma et al. [24], and Soares et al. [25].

Several studies show that this process can be influenced by exogenous factors, composition of the germination environment, and the harvesting conditions [25, 30, 41-44], but at the same time this can be a genotypic characteristic.

The highest germination percentage was recorded in S8 (74.16\%), followed by S15 (65.46\%) and S4 (56.46\%). This can be correlated with the high lipid content, an essential element in the storage of nutrients and energy necessary for germination. Lipid bodies are used as cytological markers so as to monitor the vital processes of pollen grains [41]. The results interpreted by means of the Duncan's test $(P<0.05)$ show that significant differences are recorded in S12 (9.17\%), S7 (29.51\%), S3 (45.73\%), S4 (56.46\%), S15 (65.47\%), and S8 (74.16\%) genotypes (Figure 5).

The Saintpaulia pollen germination process differed from one genotype to another. The above results show that some genotypes (Figure 5) do not reach the minimum germination level (30\%), which means that these genotypes are recommended only as maternal genitors in breeding, even if these have high pollen viability $[28,45]$. Very good results
Saintpaulia pollen germination (\%)

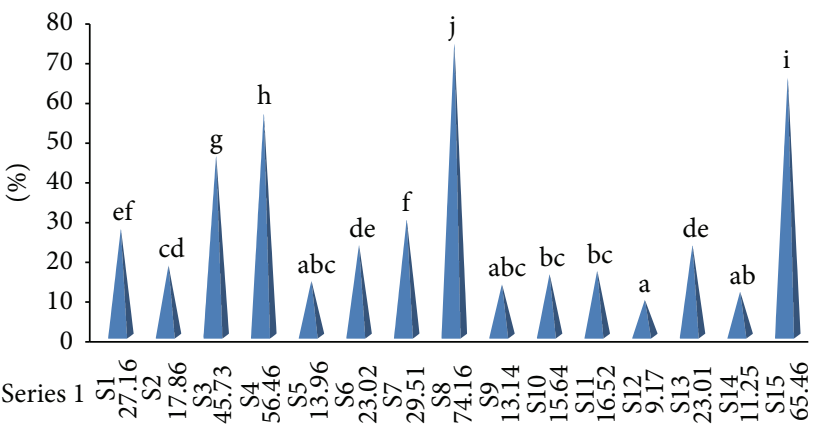

Saintpaulia genotypes

FIGURE 5: The germination percentage of the pollen grains in Saintpaulia genotypes on solid medium (15\% sucrose, $85 \%$ moisture, and $22^{\circ} \mathrm{C}$ temperature). ${ }^{*}$ Values are means of 5 replications \pm SD (5.51-6.38). Small letters represent the statistical significant differences at $P<0.05$ (Duncan's test).

regarding the viability were obtained in S3, S4, S5, S9, and S11 genotypes, which also have a rich content of polygalacturonic acids, lipids, and carbohydrates. Genotypes S8, S15, and S4 are noted for high germination capacity. Due to these qualities, the above mentioned genotypes can be used in hybridization programs as suggested by Kolehmainen and Mutikainen [3].

\section{Conclusions}

The IR spectroscopy results show that the structural and nutritional elements of pollen are present in all analyzed genotypes. The detailed interpretation of spectral bands shows that the spectral intensity of various bioactive components substantially differs from one genotype to another within the same genus. The data obtained in this study allow for the rapid expansion of the standardized FT-IR spectra and can serve as a starting point for the identification, classification, and biochemical characterization of pollen, results confirmed by Zimmermann and Kohler [16].

Genotypes S3, S4, S5, S8, S9, and S11 can be recommended as potential genitors in breeding for viability and germination purposes. The genotypic behaviour in viability and germination process probably depends on the biochemical components and the connection between them. Research in this sector should continue so as to better highlight the contribution of each element in the evolution of these biological processes, by obtaining quantitative data.

The results obtained based on the research and investigations are important in the global research programs which aim to build and introduce new genotypes of ornamental plants to be competitive in the international ornamental's assortment.

\section{Conflict of Interests}

The authors declare that there is no conflict of interests regarding the publication of this paper. 


\section{Acknowledgment}

This paper was published under the frame of European Social Fund, Human Resources Development Operational Programme 2007-2013, Project no. POSDRU/159/1.5/S/132765.

\section{References}

[1] N. Daud and R. M. Taha, "Plant regeneration and floral bud formation from intact floral parts of African violet (Saintpaulia ionantha H. Wendl.) cultured in vitro," Pakistan Journal of Biological Sciences, vol. 11, no. 7, pp. 1055-1058, 2008.

[2] Y. Ghasemi, G. A. Nematzadeh, V. G. Omran, A. Dehestani, and S. Hosseini, "The effects of explant type and phytohormones on African violet (Saintpaulia ionantha) micropropagation efficiency," Biharean Biologist, vol. 6, no. 2, Article ID 121109, pp. 73-76, 2012.

[3] J. Kolehmainen and P. Mutikainen, "Population stage structure, survival and recruitment in the endangered East African forest herb Saintpaulia," Plant Ecology, vol. 192, no. 1, pp. 85-95, 2007.

[4] F. Toma, Floriculture and Floral Art-Volume 3: Pot Plants and Indoor Plants, Invel Multimedia, Bucureşti, Romania, 2009.

[5] J.-Y. Fang and S. Traore, "In vitro mutation induction of Saintpaulia using ethyl methanesulfonate," HortScience, vol. 46, no. 7, pp. 981-984, 2011.

[6] E. Şelaru, Indoor Plants, Ceres, Bucharest, Romania, 2006.

[7] L. Draghia and E. L. Chelariu, Floriculture, Ion Ionescu de la Brad, Iaşi, Romania, 2011.

[8] C. J. Harrison, M. Möller, and Q. C. B. Cronk, "Evolution and development of floral diversity in Streptocarpus and Saintpaulia," Annals of Botany, vol. 84, no. 1, pp. 49-60, 1999.

[9] P. F. Stevens, “Angiosperm Phylogeny Website," 2001, http:// www.mobot.org/MOBOT/research/APweb/.

[10] A. Toogood, Plant Propagation: The Fully Illustrated Plant-byPlant Manual of Practical Techniques, DK Publishing, New York, NY, USA, 1999.

[11] D. S. Poşta, "Impact of biostimulators and of rooting substratum on sapling growth in Ficus carica L.-part II," Journal of Horticulture, Forestry and Biotechnology, vol. 16, no. 3, pp. 73-78, 2012.

[12] M. Mularczyk-Oliwa, A. Bombalska, M. Kaliszewski et al., "Comparison of fluorescence spectroscopy and FTIR in differentiation of plant pollens," Spectrochimica Acta, Part A: Molecular and Biomolecular Spectroscopy, vol. 97, pp. 246-254, 2012.

[13] A. Bombalska, M. Mularczyk-Oliwa, B. Jankiewicz et al., "Application of FTIR and SERS spectroscopy in analysis and discrimination of bacteria and their interferents," Biomedical Spectroscopy and Imaging, vol. 3, pp. 29-39, 2014.

[14] B. Zimmermann, Z. Tkalčec, A. Mešić, A. Kohler, and J. Yu, "Characterizing aeroallergens by infrared spectroscopy of fungal spores and pollen," PLOS ONE, vol. 10, no. 4, Article ID e0124240, 2015.

[15] C. S. Pappas, P. A. Tarantilis, P. C. Harizanis, and M. G. Polissiou, "New method for pollen identification by FT-IR spectroscopy," Applied Spectroscopy, vol. 57, no. 1, pp. 23-27, 2003.

[16] B. Zimmermann and A. Kohler, "Infrared spectroscopy of pollen identifies plant species and genus as well as environmental conditions," PLoS ONE, vol. 9, no. 4, Article ID e95417, 2014.
[17] E. Gottardini, S. Rossi, F. Cristofolini, and L. Benedetti, "Use of Fourier transform infrared (FT-IR) spectroscopy as a tool for pollen identification," Aerobiologia, vol. 23, no. 3, pp. 211-219, 2007.

[18] B. Zimmermann and A. Kohler, "Shedding light on plant biology by Fourier transform infrared spectroscopy of pollen," SpectroscopyEurope, vol. 26, no. 4, pp. 20-23, 2014.

[19] G. Parodi, P. Dickerson, and J. Cloud, "Pollen identification by fourier transform infrared photoacoustic spectroscopy," Applied Spectroscopy, vol. 67, no. 3, pp. 342-348, 2013.

[20] R. Lahlali, Y. Jiang, S. Kumar et al., "ATR-FTIR spectroscopy reveals involvement of lipids and proteins of intact pea pollen grains to heat stress tolerance," Frontiers in Plant Science, vol. 5, article 747, 10 pages, 2014.

[21] M. M. Hockenberry and D. B. White, "In vitro pollen germination in fountain grass," Hortscience, vol. 29, p. 920, 1994.

[22] Z. Huang, J. Zhu, X. Mu, and J. Lin, "Pollen dispersion, pollen viability and pistil receptivity in Leymus chinensis," Annals of Botany, vol. 93, no. 3, pp. 295-301, 2004.

[23] S. P. Gudadhe and V. S. Dhoran, "Observation on pollen viability, in vitro pollen germination and pollen tube growth in Chlorophytum comosum (Thunb) Jacq. and Asparagus officinalis, L.," International Journal of Current Research, vol. 4, no. 7, pp. 22-27, 2012.

[24] K. Bodhipadma, S. Noichinda, I. Yadbuntung, W. Buaeiam, and D. W. M. Leung, "Comparison of in vitro and in vivo inflorescence of common cockscomb (Celosia argentea var. cristata)," ScienceAsia, vol. 36, no. 1, pp. 68-71, 2010.

[25] T. L. Soares, O. N. De Jesus, J. A. Dos Santos-Serejo, and E. J. De Oliveira, "In vitro pollen germination and pollen viability in passion fruit (Passiflora spp.)," Revista Brasileira de Fruticultura, vol. 35, no. 4, pp. 1116-1126, 2013.

[26] W. A. Pline, K. L. Edmisten, T. Oliver, J. W. Wilcut, R. Wells, and N. S. Allen, "Use of digital image analysis, viability stains, and germination assays to estimate conventional and glyphosateresistant cotton pollen viability," Crop Science, vol. 42, no. 6, pp. 2193-2200, 2002.

[27] R. Sestraş, Plant Breeding, Academic Press, Cluj-Napoca, Romania, 2012

[28] M. I. Cordea, Plant Breeding-Practical Works, AcademicPres, Cluj-Napoca, Romania, 2014.

[29] K. Bodhipadma, S. Noichinda, P. Thaiyanto, and D. W. M. Leung, "Morphology, viability, and germinability of pollen from two forms of Nymphaea nouchali var. versicolor, a day-blooming waterlily," ScienceAsia, vol. 39, no. 2, pp. 214-218, 2013.

[30] S. Žilić, J. Vančetović, M. Janković, and V. Maksimović, “Chemical composition, bioactive compounds, antioxidant capacity and stability of floral maize (Zea mays L.) pollen," Journal of Functional Foods, vol. 10, pp. 65-74, 2014.

[31] J. Yang and H. E. Yen, "Early salt stress effects on the changes in chemical composition in leaves of ice plant and Arabidopsis. A fourier transform infrared spectroscopy study," Plant Physiology, vol. 130, no. 2, pp. 1032-1042, 2002.

[32] J. Coates, "Intrepretation of infrared spectra. A practical approach," in Encyclopedia of Analytical Chemistry, John Wiley \& Sons, Chichester, UK, 2000.

[33] C. F. B. Séné, M. C. McCann, R. H. Wilson, and R. Grinter, "Fourier-transform Raman and fourier-transform infrared spectroscopy. An investigation of five higher plant cell walls and their components," Plant Physiology, vol. 106, no. 4, pp. 1623$1631,1994$. 
[34] Q. Wang, L. Kong, H. Hao et al., "Effects of brefeldin A on pollen germination and tube growth. Antagonistic effects on endocytosis and secretion," Plant Physiology, vol. 139, no. 4, pp. 16921703, 2005.

[35] C. Petrişor, V. Mitre, I. Mitre, L. Jantschi, and C. M. Balan, “The rate of pollen germination and the pollen viability at ten apple cultivars in the climatic conditions of Transylvania," Bulletin UASMV-Horticulture, vol. 69, no. 1, pp. 417-418, 2012.

[36] T. Rodriguez-Riano and A. Dafni, "A new procedure to asses pollen viability," Sexual Plant Reproduction, vol. 12, no. 4, pp. 241-244, 2000.

[37] D. H. Firmage and A. Dafni, "Field tests for pollen viability; a comparative approach," Acta Horticulturae, vol. 561, pp. 87-94, 2001.

[38] S. Fei and E. Nelson, "Estimation of pollen viability, shedding pattern, and longevity of creeping bentgrass on artificial media," Crop Science, vol. 43, no. 6, pp. 2177-2181, 2003.

[39] F. De Assis Sinimbú Neto, A. B. G. Martins, and J. C. Barbosa, "In vitro viability of 'bacury' pollen grains," Revista Brasileira de Fruticultura, vol. 33, no. 2, pp. 593-600, 2011.

[40] S. Ahmad, A. Rana, R. Sharma, and R. K. Agnihotri, "Effect of different media and boric acid on pollen germination and tube growth of Tribulus terrestris-a traditional medicinal plant," International Journal of Pharmaceutical Sciences Review and Research, vol. 13, no. 2, pp. 77-79, 2012.

[41] M. I. Rodríguez-García, M. M’rani-Alaoui, and M. C. Fernán$\mathrm{dez}$, "Behavior of storage lipids during development and germination of olive (Olea europaea L.) pollen," Protoplasma, vol. 221, no. 3-4, pp. 237-244, 2003.

[42] G. Aronne, V. De Micco, and M. Scala, "Effects of relative humidity and temperature conditions on pollen fluorochromatic reaction of Rosmarinus officinalis L. (Lamiaceae)," Protoplasma, vol. 228, no. 1-3, pp. 127-130, 2006.

[43] S. Pădureanu, "Cytology of Viola odorata L. pollen germination," Scientific Annals of Alexandru Ioan Cuza University of Iasi. New Series, Section 2. Vegetal Biology, vol. 50, pp. 60-69, 2007.

[44] A. M. Sani, A. H. Kakhki, and E. Moradi, "Chemical composition and nutritional value of saffron's pollen (Crocus sativus L.)," Nutrition \& Food Science, vol. 43, no. 5, pp. 490-495, 2013.

[45] R. E. Sestraș, M. Ardelean, I. M. Cordea, and A. F. Sestraş, Biostatistics and Forestry Experimental Technique-Support for Practical Work, AcademicPres, Cluj-Napoca, Romania, 2012. 

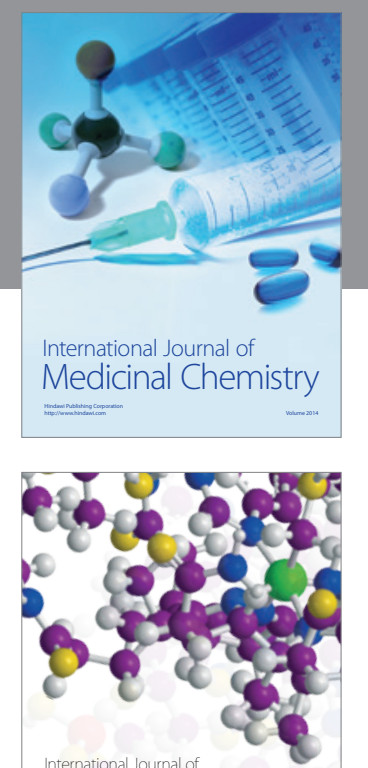

\section{Carbohydrate} Chemistry

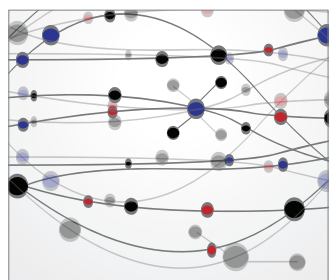

The Scientific World Journal
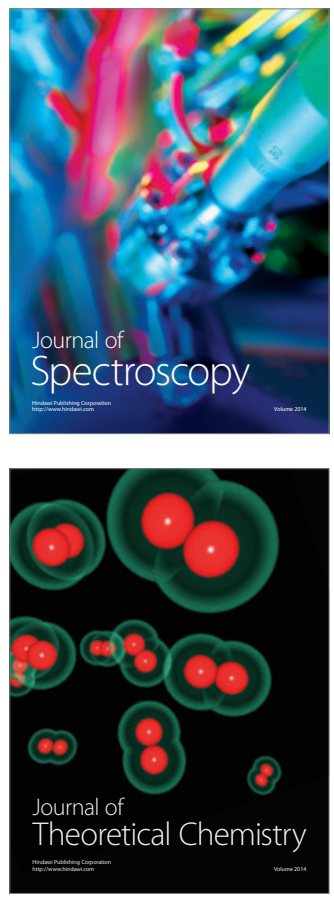
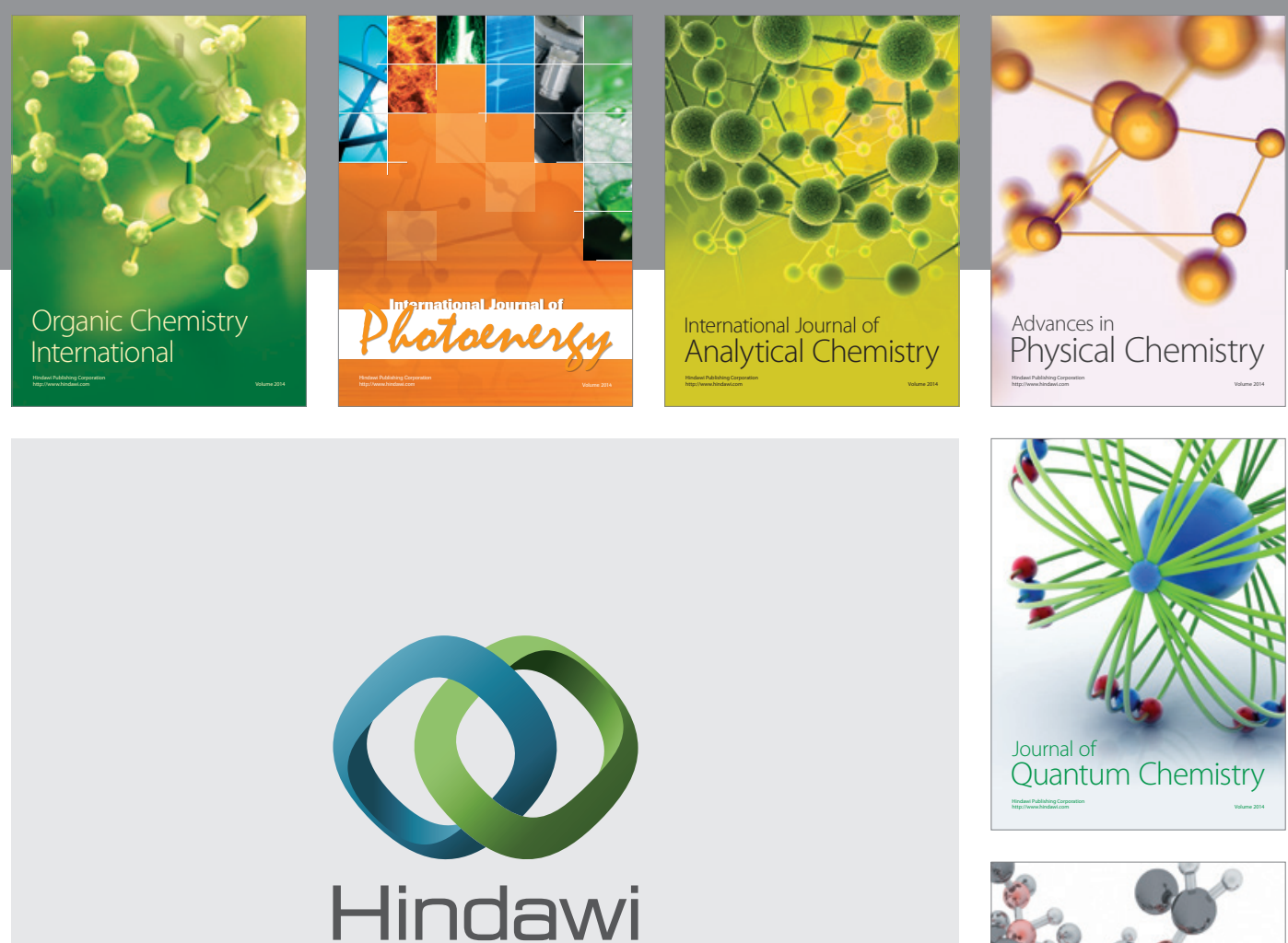

Submit your manuscripts at

http://www.hindawi.com

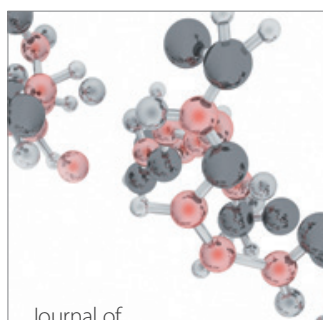

Analytical Methods

in Chemistry

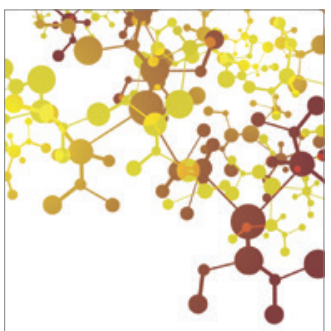

Journal of

Applied Chemistry

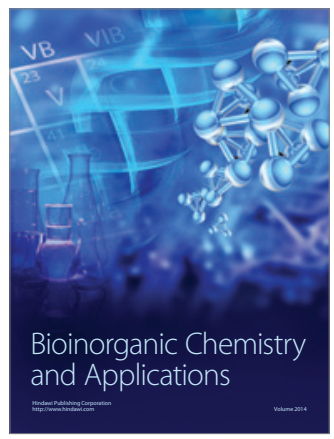

Inorganic Chemistry
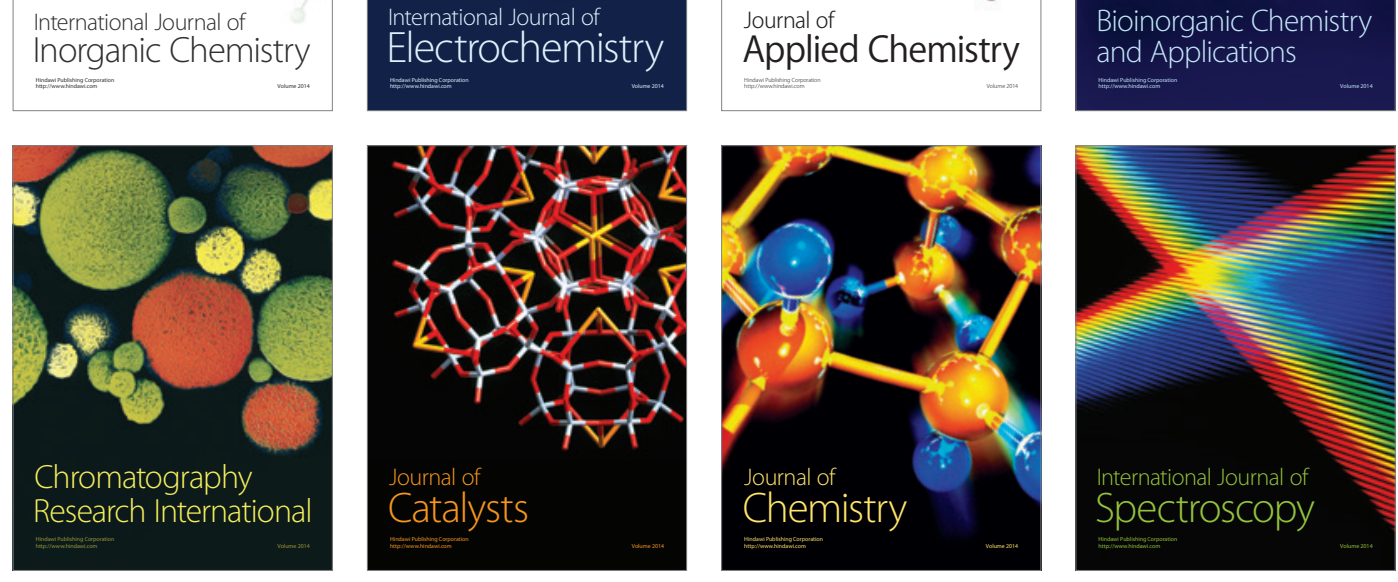